\title{
ACUTE HYPOXIA AND REOXYGENATION IMPAIRS EXHALED NITRIC OXIDE RELEASE AND PULMONARY MECHANICS
}

Jeffrey M. Pearl, MD

David P. Nelson, MD, PhD

Scott A. Wellmann, MD

Jenni L. Raake, RRT

Connie J. Wagner, BS

Jerri L. McNamara, CCP

Jodie Y. Duffy, PhD
Objective: Changes in exhaled nitric oxide levels often accompany conditions associated with elevated pulmonary vascular resistance and altered lung mechanics. However, it is unclear whether changes in exhaled nitric oxide reflect altered vascular or bronchial nitric oxide production. This study determined the effects of acute hypoxia and reoxygenation on pulmonary mechanics, plasma nitrite levels, and exhaled nitric oxide production.

Methods: Ten piglets underwent 90 minutes of hypoxia (fraction of inspired oxygen $=12 \%$ ), 1 hour of reoxygenation on cardiopulmonary bypass, and 2 hours of recovery. Five additional animals underwent bypass without hypoxia. Exhaled nitric oxide, plasma nitrite levels, and pulmonary mechanics were measured.

Results: Exhaled nitric oxide decreased to $36 \%$ of baseline by end hypoxia (34 \pm 14 vs $12 \pm 9$ ppb, $P=.005$ ) and declined further to $20 \%$ of baseline at end recovery ( $7 \pm 6 \mathrm{ppb})$. Aortic nitrite levels decreased from baseline during hypoxia (from $102 \pm 13$ to $49 \pm 7 \mu \mathrm{mol} / \mathrm{L}, P=.05$ ) but returned to baseline during recovery. Pulmonary arterial nitrite also decreased during hypoxia (from $31.4 \pm 7.8$ to $22.9 \pm 9.5 \mu \mathrm{mol} / \mathrm{L}, P=.04$ ) and returned to baseline at end recovery. Decreased production of exhaled nitric oxide was associated with impaired gas exchange (alveolar-arterial gradient $=32 \mathrm{~mm} \mathrm{Hg}$ at baseline and $84 \mathrm{~mm} \mathrm{Hg}$ at end recovery), decreased pulmonary compliance $\left(6.6 \pm 0.9 \mathrm{~mL} / \mathrm{cm} \mathrm{H}_{2} \mathrm{O}\right.$ at baseline, $5.0 \pm 0.7 \mathrm{~mL} / \mathrm{cm} \mathrm{H}_{2} \mathrm{O}$ at end hypoxia, and $5.4 \pm 0.7 \mathrm{~mL} / \mathrm{cm} \mathrm{H}_{2} \mathrm{O}$ at end recovery), and increased inspiratory airway resistance $\left(41 \pm 4 \mathrm{~cm} \mathrm{H} \mathrm{H}_{2} \mathrm{O} \cdot \mathrm{L}^{-1} \cdot \mathrm{s}^{-1}\right.$ at baseline, $56 \pm 4.9 \mathrm{~cm} \mathrm{H}_{2} \mathrm{O} \cdot \mathrm{L}^{-1} \cdot \mathrm{s}^{-1}$ at end hypoxia, and $50 \pm 5 \mathrm{~cm} \mathrm{H}_{2} \mathrm{O} \cdot \mathrm{L}^{-1} \cdot \mathrm{s}^{-1}$ at end recovery).

Conclusions: A decrease in exhaled nitric oxide persisted after hypoxia, and plasma nitrite levels returned to baseline on reoxygenation, indicating that alterations in exhaled nitric oxide during hypoxia-reoxygenation might be unrelated to plasma nitrite levels. Furthermore, decreased exhaled nitric oxide corresponded with altered pulmonary mechanics and gas exchange. Reduced exhaled nitric oxide after hypoxia-reoxygenation might reflect bronchial epithelial dysfunction associated with acute lung injury. (J Thorac Cardiovasc Surg 2000;119:931-8)
From Children's Hospital Medical Center, Cincinnati, Ohio.

Read at the Seventy-first Scientific Sessions, American Heart Association meeting, Dallas, Tex, November 1998.

Received for publication May 14, 1999; revisions requested July 26, 1999; revisions received Nov 29, 1999; accepted for publication Dec 13, 1999.

Address for reprints: Jeffrey M. Pearl, MD, Assistant Professor of Surgery, Division of Cardiothoracic Surgery, Children's Hospital Medical Center, OSB-3, 3333 Burnet Ave, Cincinnati, OH 45229 (E-mail: pearj0@chmcc.org).

Copyright $@ 2000$ by The American Association for Thoracic Surgery $0022-5223 / 2000 \$ 12.00+0 \quad \mathbf{1 2 / 1 / 1 0 5 0 5 6}$

doi: $10.1067 / \mathrm{mtc} .2000 .105056$
Decent evidence suggests that measurement of Rexhaled nitric oxide (NO) might serve as a marker of altered pulmonary function. Elevated levels of exhaled NO have been demonstrated in chronic bronchial asthma, ${ }^{1-3}$ whereas decreased levels have been found in more acute conditions, such as acute respiratory distress syndrome and congestive heart failure. ${ }^{4,5}$ Altered levels of exhaled NO have also been found in smokers compared with nonsmokers, suggesting that bronchial epithelial injury can affect exhaled NO levels. Similarly, acute lung injury, such as that occurring during reoxygenation after hypoxia, might 
also affect exhaled NO. The relationship between exhaled NO and vascular-derived NO, estimated by plasma nitrite and nitrate levels, is unclear. Evidence suggests that a significant amount of exhaled NO is derived from the bronchial epithelium rather than originating from $\mathrm{NO}$ in the vascular compartment. Furthermore, the presence of nitric oxide synthase (NOS) II in the bronchial epithelium confirms a potential distinct source of NO production outside the vascular compartment. ${ }^{6}$

With the identification of NOS II in the bronchial epithelium and the advent of technology to measure exhaled NO interest arose in the role of exhaled NO during homeostatic, as well as pathologic conditions. Specifically, it was hypothesized that changes in exhaled NO levels in conditions associated with altered pulmonary mechanics and gas exchange might be a direct result of restricted bronchial epithelial function and NOS activity. Our model of acute hypoxia with reoxygenation resulted in acute lung injury. ${ }^{7}$ We hypothesized that exhaled NO might serve as a marker for lung injury in our model and furthermore that exhaled NO does not correlate with plasma nitrite levels. We reasoned that changes in exhaled NO were associated with altered pulmonary mechanics seen during hypoxia-reoxygenation. This study investigated these hypotheses by using an established neonatal piglet model of hypoxia and reoxygenation.

\section{Materials and methods}

Neonatal 2-week-old piglets weighing 4 to $6 \mathrm{~kg}$ were used in this study. Animals received humane care in compliance with the "Principles of Laboratory Animal Care" formulated by the National Society for Medical Research and the "Guide for the Care and Use of Laboratory Animals" prepared by the Institute of Laboratory Animal Resources and published by the National Institutes of Health (National Institutes of Health publication No. 85-23, revised 1985).

An established model of hypoxia-reoxygenation from our laboratory was used. ${ }^{7}$ The piglets were anesthetized with ketamine, intubated with a cuffed endotracheal tube, and mechanically ventilated by using a volume-controled ventilator (Siemens 900B; Siemens-Elema, Solna, Sweden). A constant inhaled tidal volume of $18 \mathrm{~mL} / \mathrm{kg}$ was maintained with an initial fraction of inspired oxygen $\left(\mathrm{FIO}_{2}\right)$ of $40 \%$. Femoral arterial and venous lines were placed. Deep sedation and paralysis were maintained by an infusion of nembutal $(20 \mathrm{mg}$ $\left.\cdot \mathrm{kg}^{-1} \cdot \mathrm{h}^{-1}\right)$, intermittent fentanyl $\left(10 \mu \mathrm{g} \cdot \mathrm{kg}^{-1} \cdot \mathrm{h}^{-1}\right)$, and pancuronium $\left(0.2 \mathrm{mg} \cdot \mathrm{kg}^{-1} \cdot \mathrm{h}^{-1}\right)$. Arterial blood gasses were measured, and co-oximetry was performed every 15 minutes (Chiron Diagnostics Co, East Walpole, Mass).

Transducer-tipped catheters (Millar Instruments Inc, Houston, Tex) were placed in the pulmonary artery and in the right and left ventricles for measuring right ventricular end- diastolic pressure and left ventricular end-diastolic pressure. A Doppler flow probe placed around the pulmonary arterial trunk (T206; Transonic Systems, Inc, Ithaca, NY) was used to monitor cardiac output.

The alveolar $\mathrm{Po}_{2}$ at an $\mathrm{FIO}_{2}$ of $40 \%$ was calculated by the alveolar gas equation to allow determination of alveolar-arterial gradient. Dynamic airway compliance (Cdyn) and inspiratory airway resistance $(\mathrm{RaW})$ were measured by using the $\mathrm{CO}_{2} \mathrm{SMO}$ Plus Respiratory Profile Monitor (Novametrix Medical Systems, Inc, Wallingford, Conn). Inspiratory tidal volume was kept constant, and measurements from 10 consecutive breaths were averaged to determine RaW and Cdyn.

Exhaled NO was measured by a Sievers chemiluminescence NO monitor (NOA 270B; Sievers Medical Instruments Inc, Boulder, Colo). Exhaled NO was measured throughout the exhalation cycle with both a peak and a mean value determined by the NOA software (Breath-By-Breath Exhaled NO Software, Version 2.11, Sievers Instruments, Inc). Chemiluminescence NO measurement involved an electrical signal proportional to the light generated from a reaction between NO and ozone. Other laboratories have validated this technique for measuring exhaled NO${ }^{8}$ The mean exhaled NO value was the average peak value over 10 breaths.

After a 30-minute equilibration period, baseline hemodynamic measurements and arterial blood samples were obtained. The inhaled $\mathrm{FIO}_{2}$ was decreased to $12 \%$ to induce hypoxia, resulting in a systemic saturation of $65 \%$ to $70 \%$. Hemodynamic measurements and arterial blood samples were taken at $5,15,30,45,60,75$, and 90 minutes of hypoxia. Animals were administered fluid boluses of 5 to $10 \mathrm{~mL} / \mathrm{kg}$ of $0.9 \%$ sodium chloride as needed to maintain a mean arterial pressure above $35 \mathrm{~mm} \mathrm{Hg}$, with a volume limit of 40 $\mathrm{mL} / \mathrm{kg}$. Sodium bicarbonate was given, if needed, to maintain blood $\mathrm{pH}$ above 7.3. The ventilator rate was adjusted to maintain the $\mathrm{PCO}_{2}$ between 38 and $42 \mathrm{~mm} \mathrm{Hg}$. The tidal volume remained at $18 \pm 1 \mathrm{~mL} / \mathrm{kg}$ to ensure that changes in pulmonary mechanics accurately reflected alterations in the lungs and were not caused by ventilator manipulation.

After 90 minutes of hypoxia, animals were placed on cardiopulmonary bypass $(\mathrm{CPB})$ with a bypass circuit $\mathrm{Po}_{2}$ greater than $450 \mathrm{~mm} \mathrm{Hg}$. CPB was incorporated to simulate a newborn undergoing repair of congenital heart defects. Arterial cannulation was through the right carotid artery, and venous cannulation was through the right atrial appendage. The ventilator $\mathrm{FIO}_{2}$ was increased to $100 \%$ during $\mathrm{CPB}$, and the rate decreased to 4 breaths per minute to prevent atelectasis. Animals were not actively cooled and were not allowed to drift below a rectal body temperature of $32^{\circ} \mathrm{C}$ to minimize the effects of hypothermia. Flow rates on CPB were maintained at $100 \mathrm{~mL} \cdot \mathrm{kg}^{-1}$. $\mathrm{min}^{-1}$, with a minimum mean arterial pressure of $35 \mathrm{~mm} \mathrm{Hg}$.

After 1 hour of $\mathrm{CPB}$, animals were warmed to $38^{\circ} \mathrm{C}$, weaned from $\mathrm{CPB}$, and returned to normoxic conditions $\left(\mathrm{FIO}_{2}\right.$ $=40 \%$ ). The animals were maintained under similar conditions as baseline for 2 hours. Blood samples were obtained for the measurement of aortic and pulmonary arterial nitrite, and exhaled NO and hemodynamics were recorded at 15, 30, 60 , and 120 minutes of recovery. 
An additional 5 animals (group II) were instrumented, maintained at normoxia $\left(\mathrm{FIO}_{2}=40 \%\right)$ for 90 minutes, placed on $\mathrm{CPB}$ for 1 hour, and allowed to recover for an additional 2 hours. These animals served as controls to demonstrate any changes from $\mathrm{CPB}$ alone. Other investigators have confirmed the minimal effect of bypass in similar models. ${ }^{9}$

Tissue myeloperoxidase assay. Frozen lung samples collected at baseline, end hypoxia, and end recovery were homogenized in $1 \mathrm{~mL}$ of a solution containing $0.5 \%$ hexadecyltrimethyl-ammonium bromide dissolved in $10 \mathrm{mmol} / \mathrm{L} \mathrm{3-}$ [ $N$-morpholino]propanesulfonic acids and then centrifuged at $21,000 \mathrm{~g}$ for 20 minutes at $4^{\circ} \mathrm{C}$. The supernatant $(100 \mu \mathrm{L})$ was mixed with $700 \mu \mathrm{L}$ of sodium phosphate $(80 \mathrm{mmol} / \mathrm{L}, \mathrm{pH}$ $5.5)$ and $100 \mu \mathrm{L}$ of tetramethyl benimide $(16 \mathrm{mmol} / \mathrm{L})$ and incubated at $25^{\circ} \mathrm{C}$ for 5 minutes. Then $100 \mu \mathrm{L}$ of $1 \mathrm{mmol} / \mathrm{L}$ hydrogen peroxide was added and incubated for exactly 3 minutes at $25^{\circ} \mathrm{C}$. A blank without hydrogen peroxide was also analyzed for each tissue. The reaction was stopped by the addition of $1 \mathrm{~mL}$ of cold acetic acid $(2 \mathrm{~mol} / \mathrm{L})$. The optical density was measured at $650 \mathrm{~nm}$ on a spectrophotometer (Labsystems Multiscan MCC/340, Franklin, Mass). Myeloperoxidase (MPO) activity was expressed as units per $50 \mathrm{mg}$ of tissue per 3 minutes. MPO activity is representative of leukocyte activity in the tissue.

Tissue lipid peroxidase assay. Frozen lung tissue was homogenized in 10 volumes $(1 \mathrm{~mL} / 100 \mathrm{mg}$ ) of $10 \%$ (vol/vol) $1.15 \%$ potassium chloride on ice. A modified thiobarbituric acid reaction technique was used. The optical density at 532 $\mathrm{nm}$ was measured, and concentration was determined by using a Spectronic Genesys spectrophotometer (Spectronic Instruments, Rochester, NY). Concentrations were calculated with the use of standard solutions of malondialdehydedimethylacetate (0.5-16 nmol) and expressed as nanomoles per $100 \mathrm{mg}$ of wet tissue. Tissue lipid peroxidase measurements are an indication of membrane peroxidation, a marker of free radical-mediated injury.

Nitrite assay. Blood levels of NO were estimated by measurement of aortic and pulmonary arterial nitrate and nitrite by using a 2-part assay converting nitrate to nitrite by the Griess reaction. ${ }^{10,11}$ The optical density of each well was read at $550 \mathrm{~nm}$, with correction at $650 \mathrm{~nm}$ (Labsystems Multiscan $\mathrm{MCC} / 340)$. The data were analyzed by using GENESIS software (Fisher Scientific Co, Pittsburgh, Pa), and total nitrite levels (in micromoles per liter) were reported. Pulmonary arterial nitrite values were not obtained from 2 animals, and values from 2 other animals were several SDs from the mean and were excluded secondary to presumed collection or processing error. Hence, pulmonary arterial nitrite values are reported from 6 animals compared with 10 animals for the aortic nitrite values.

Statistical analysis. Data were reported as the mean \pm SD. Analysis of variance and the 2-tailed paired Student $t$ test were used to compare values at different time points. A $P$ value of less than or equal to .05 was considered significant (Statview 4.01 software; Abacus Concepts Inc, Berkeley, Calif).

\section{Results}

Animals demonstrated a general descending trend in hemodynamics during hypoxia, with only partial recovery after reoxygenation (Table I). Cardiac output dropped by as much as $40 \%$ by end hypoxia and was only $72 \%$ of prehypoxia values at end recovery. Oxygen delivery at end recovery was $57 \%$ of baseline. Cardiac output and oxygen delivery in group II animals were not different from baseline at end recovery $(91 \%$ and $84 \%$, respectively).

Pulmonary vascular resistance (PVR) increased promptly with the onset of hypoxia in all group I animals (Fig 1). PVR increased $515 \%$ by end hypoxia ( $P$ $=.005)$ from a baseline of $66 \pm 14$ to $340 \pm 42$ dynes . $\mathrm{s}^{-1} \cdot \mathrm{cm}^{-5}$. PVR decreased after reoxygenation on CPB but did not return to baseline by end recovery $(146 \pm 21$ dynes $\cdot \mathrm{s}^{-1} \cdot \mathrm{cm}^{-5}, 221 \%$ of baseline; $\left.P=.04\right)$. In conjunction with the rise in PVR, both aortic and pulmonary arterial nitrite decreased. Aortic nitrite decreased to less than one half of the baseline value $(102 \pm 13$ vs $49 \pm 7 \mu \mathrm{mol} / \mathrm{L}, P=.05)$ but returned to baseline by end recovery $(96 \pm 8 \mu \mathrm{mol} / \mathrm{L}, P>.2)$ despite the persistence of significantly elevated PVR. Pulmonary arterial nitrite had a similar but less pronounced decrease during hypoxia and return to baseline after reoxygenation (Fig 1). In group II PVR remained unchanged before $\mathrm{CPB}$ and increased by no more than $25 \%$ in any animal after $\mathrm{CPB}$ and recovery $\left(78 \pm 15\right.$ dynes $\cdot \mathrm{s}^{-1} \cdot \mathrm{cm}^{-5}$ at baseline vs $96 \pm 14$ dynes $\cdot \mathrm{s}^{-1} \cdot \mathrm{cm}^{-5}$ at end recovery).

Baseline mean exhaled NO in group I was $34 \pm 14$ ppb and remained stable during baseline normoxia. During hypoxia, exhaled NO decreased to $35 \%$ of baseline by end hypoxia (12 \pm 9 ppb, $P=.005$; Fig 1$)$. The $70 \%$ decrease in exhaled NO was associated with a $54 \%$ decrease in aortic nitrite levels and a $27 \%$ decrease in pulmonary arterial nitrite levels. However, unlike aortic and pulmonary arterial nitrite levels that returned to baseline levels after reoxygenation, exhaled NO decreased further despite the restoration of normoxic conditions ( $7 \pm 6 \mathrm{ppb}$ at end recovery, $P=.005$ compared with baseline; Fig 1). In group II exhaled NO was not different from baseline at end recovery $(26 \pm 9$ vs $25 \pm 8 \mathrm{ppb}, P>$.2).

Impairment in exhaled NO production was associated with alterations in pulmonary function and mechanics. Dynamic pulmonary compliance decreased significantly from $6.6 \pm 0.9 \mathrm{~mL} / \mathrm{cm} \mathrm{H}_{2} \mathrm{O}$ at baseline to $5.0 \pm$ $0.7 \mathrm{~mL} / \mathrm{cm} \mathrm{H}_{2} \mathrm{O}$ at end hypoxia and $5.4 \mathrm{~mL} / \mathrm{cm} \mathrm{H}_{2} \mathrm{O}$ at end recovery ( $P=.05$ compared with baseline; Fig 2$)$. Concomitant with the decrease in Cdyn, RaW increased over baseline during hypoxia and reoxygena- 
Table I. Cardiopulmonary, exhaled nitric oxide, and vascular nitrite data during hypoxia or normoxia and recovery in neonatal pigs

\begin{tabular}{|c|c|c|c|c|c|}
\hline & $\begin{array}{l}\text { CPB controls* } \\
(\text { group } I I, n=5)\end{array}$ & $\begin{array}{l}\mathrm{P} \text { value versus } \\
\text { baseline }\end{array}$ & $\begin{array}{c}\text { Hypoxia/reoxygenation } \dagger \\
(\text { group } I, n=10)\end{array}$ & $\begin{array}{c}\mathrm{P} \text { value versus } \\
\text { baseline }\end{array}$ & $\begin{array}{c}\text { P value versus } \\
\text { control }\end{array}$ \\
\hline \multicolumn{6}{|l|}{ PVR (dynes $\cdot \mathrm{s}^{-1} \cdot \mathrm{cm}^{-5}$ ) } \\
\hline Baseline & $78 \pm 15$ & & $66 \pm 14$ & & $>.2$ \\
\hline Hypoxia or normoxia (15 min) & $85 \pm 13$ & $>.2$ & $260 \pm 20$ & .01 & .005 \\
\hline Hypoxia or normoxia (90 min) & $85 \pm 13$ & $>.2$ & $340 \pm 42$ & .01 & .005 \\
\hline Recovery (60 min) & $101 \pm 16$ & $>.2$ & $138 \pm 25$ & .05 & .06 \\
\hline Recovery (120 min) & $96 \pm 14$ & $>.2$ & $146 \pm 21$ & .04 & .05 \\
\hline \multicolumn{6}{|l|}{$\mathrm{RaW}\left(\mathrm{cm} \mathrm{H}_{2} \mathrm{O} \cdot \mathrm{L}^{-1} \cdot \mathrm{s}^{-1}\right)$} \\
\hline Baseline & $40 \pm 4.2$ & & $41 \pm 4.0$ & & $>.2$ \\
\hline Hypoxia or normoxia (15 min) & $41 \pm 3.8$ & $>.2$ & $48 \pm 5.1$ & .05 & .05 \\
\hline Hypoxia or normoxia (90 min) & $42 \pm 4.3$ & $>.2$ & $56 \pm 4.9$ & .03 & .04 \\
\hline Recovery (60 min) & $44 \pm 4.1$ & $>.2$ & $48 \pm 4.9$ & .05 & .06 \\
\hline Recovery (120 min) & $41 \pm 3.8$ & $>.2$ & $50 \pm 5.0$ & .04 & .03 \\
\hline \multicolumn{6}{|l|}{ Cdyn $\left(\mathrm{mL} / \mathrm{cm} \mathrm{H}_{2} \mathrm{O}\right)$} \\
\hline Baseline & $6.8 \pm 0.6$ & $>.2$ & $6.6 \pm 0.9$ & & $>.2$ \\
\hline Hypoxia or normoxia (15 min) & $6.9 \pm 0.5$ & $>.2$ & $6.3 \pm 0.9$ & .07 & .06 \\
\hline Hypoxia or normoxia (90 min) & $6.8 \pm 0.7$ & $>.2$ & $5.0 \pm 0.7$ & .05 & .03 \\
\hline Recovery (60 min) & $6.3 \pm 0.5$ & .1 & $5.3 \pm 1.0$ & .05 & .05 \\
\hline Recovery (120 min) & $6.5 \pm 0.7$ & .1 & $5.4 \pm 0.7$ & .05 & .05 \\
\hline \multicolumn{6}{|l|}{ Cardiac output (mL/min) } \\
\hline Baseline & $775 \pm 80$ & & $824 \pm 72$ & & $>.2$ \\
\hline Hypoxia or normoxia (15 min) & $790 \pm 74$ & $>.2$ & $730 \pm 76$ & .08 & $>.2$ \\
\hline Hypoxia or normoxia (90 min) & $792 \pm 71$ & $>.2$ & $490 \pm 56$ & .02 & .03 \\
\hline Recovery (60 min) & $712 \pm 78$ & $>.2$ & $641 \pm 60$ & .05 & .09 \\
\hline Recovery (120 min) & $748 \pm 64$ & $>.2$ & $590 \pm 69$ & .04 & .04 \\
\hline \multicolumn{6}{|l|}{ Exhaled NO (ppb) } \\
\hline Baseline & $29 \pm 6$ & & $34 \pm 14$ & & $>.2$ \\
\hline Hypoxia or normoxia (15 min) & $27 \pm 8$ & $>.2$ & $25 \pm 11$ & .05 & $>.2$ \\
\hline Hypoxia or normoxia (90 min) & $28 \pm 9$ & $>.2$ & $12 \pm 9$ & .01 & .008 \\
\hline Recovery (60 min) & $24 \pm 7$ & $>.2$ & $9 \pm 6$ & .01 & .008 \\
\hline Recovery (120 min) & $25 \pm 8$ & $>.2$ & $7 \pm 6$ & .01 & .01 \\
\hline \multicolumn{6}{|l|}{ Aortic nitrite $(\mu \mathrm{mol} / \mathrm{L})$} \\
\hline Baseline & $94 \pm 8$ & & $102 \pm 13$ & & $>.2$ \\
\hline Hypoxia or normoxia (15 min) & $97 \pm 5$ & $>.2$ & $74 \pm 7$ & .06 & .07 \\
\hline Hypoxia or normoxia (90 min) & $92 \pm 7$ & $>.2$ & $49 \pm 7$ & .05 & .05 \\
\hline Recovery (60 min) & $86 \pm 11$ & $>.2$ & $75 \pm 10$ & .07 & .1 \\
\hline Recovery (120 min) & $95 \pm 9$ & $>.2$ & $96 \pm 8$ & $>.2$ & $>.2$ \\
\hline \multicolumn{2}{|l|}{ Pulmonary arterial nitrite $(\mu \mathrm{mol} / \mathrm{L})$} & & $\mathrm{n}=6$ & & \\
\hline \multicolumn{2}{|l|}{ Baseline } & & $31 \pm 8$ & & \\
\hline \multicolumn{2}{|l|}{ Hypoxia or normoxia (15 min) } & & $35 \pm 9$ & .06 & \\
\hline \multicolumn{2}{|l|}{ Hypoxia or normoxia (90 min) } & & $23 \pm 3$ & .04 & \\
\hline \multicolumn{2}{|l|}{ Recovery (60 min) } & & $50 \pm 13$ & .16 & \\
\hline \multicolumn{2}{|l|}{ Recovery (120 min) } & & $41 \pm 5$ & $>.2$ & \\
\hline
\end{tabular}

Values are means $\pm \mathrm{SD}$

* $C P B$ controls indicates animals subjected to 90 minutes of normoxia followed by 1 hour of reoxygenation on CPB and 2 hours of normoxic recovery.

$\dagger$ Hypoxia/reoxygenation indicates animals subjected to 90 minutes of hypoxia followed by 1 hour of reoxygenation on CPB and 2 hours of normoxic recovery

tion $\left(41 \pm 4 \mathrm{~cm}\right.$ of $\mathrm{H}_{2} \mathrm{O} \cdot \mathrm{L}^{-1} \cdot \mathrm{s}^{-1}$ at baseline, $56 \pm 4.9$ $\mathrm{cm} \mathrm{H}_{2} \mathrm{O} \cdot \mathrm{L}^{-1} \cdot \mathrm{s}^{-1}$ at end hypoxia, and $50 \pm 5 \mathrm{~cm} \mathrm{H}_{2} \mathrm{O}$ $\cdot \mathrm{L}^{-1} \cdot \mathrm{s}^{-1}$ at end recovery; Fig 2). Gas exchange in group I, as determined by alveolar-arterial gradient, was significantly lower after reoxygenation than at baseline ( 84 vs $32 \mathrm{~mm} \mathrm{Hg}, P=.005$ ). In contrast, the alveolar-arterial gradient was only slightly above the baseline level in group II animals after CPB (41 vs 53 $\mathrm{mm} \mathrm{Hg}, P=.11)$. RaW and Cdyn were not significantly changed from baseline at end recovery in group II (Table I).

Concurrent with the impaired pulmonary mechanics and decreased exhaled NO after reoxygenation there was an increase in leukocyte-mediated injury, 
Volume 119, Number 5
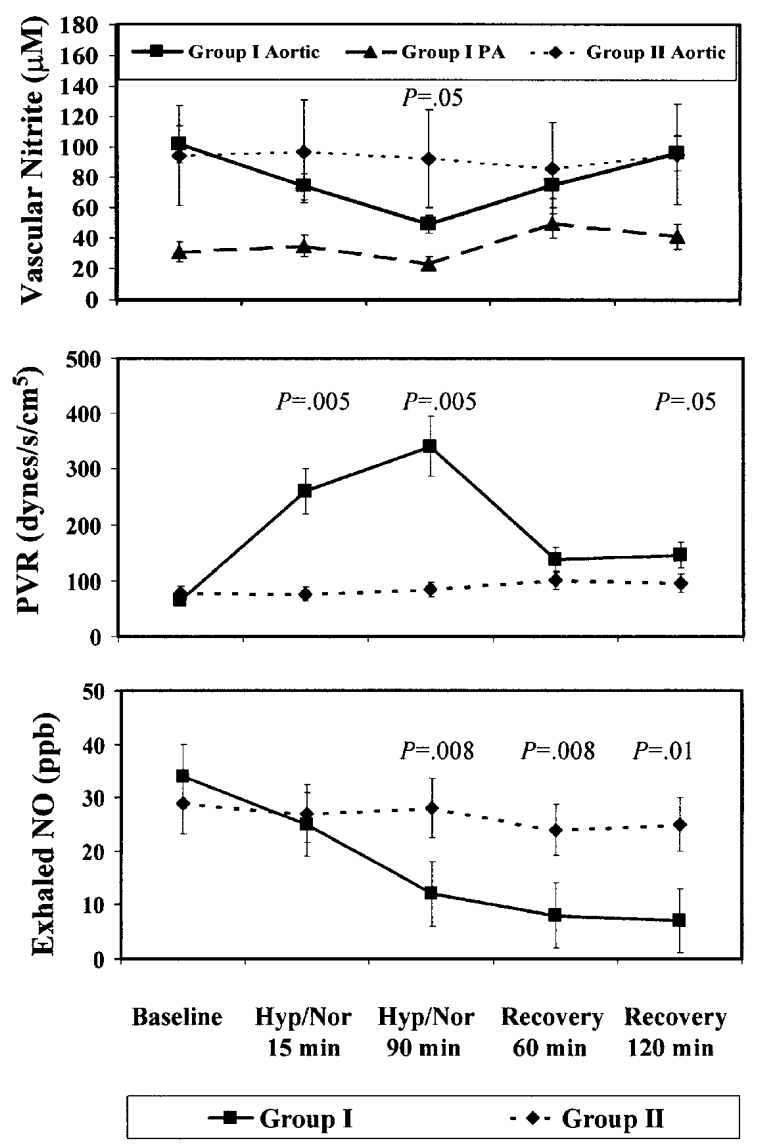

Fig 1. A comparison of changes in PVR with arterial nitrite and exhaled nitric oxide in groups I and II. Top, Aortic and pulmonary arterial nitrite levels in group I decreased at end hypoxia and returned to baseline levels by end recovery. Center, PVR increased in group I by 15 minutes of hypoxia, remained elevated during hypoxia, and then returned almost to baseline by end recovery. Bottom, Exhaled nitric oxide levels decreased below baseline levels by end hypoxia and remained lower through recovery, suggesting bronchial epithelial injury. PVR, nitrite, and exhaled nitric oxide levels in group II did not change throughout hypoxia and recovery. $P$ values are group I versus group II, as determined by using analysis of variance. Hyp/Nor, Hypoxia (group I) or normoxia (group II); $P A$, pulmonary artery.

as demonstrated by a marked increase in pulmonary MPO activity (Fig 3). Pulmonary lipid peroxidase (LPO) levels were also significantly increased after reoxygenation $(6.68 \pm 0.98 \mathrm{nmol} / 100 \mathrm{mg}$ of wet tissue at baseline vs $8.26 \pm 1.06 \mathrm{nmol} / 100 \mathrm{mg}$ of wet tissue at end recovery, $P=.008$; Fig 3 ). CPB alone did not result in significant increases in pulmonary MPO activity or LPO levels. MPO activity increased only slightly from $0.18 \pm 0.06 \mathrm{U} / 50 \mathrm{mg}$ of wet tissue
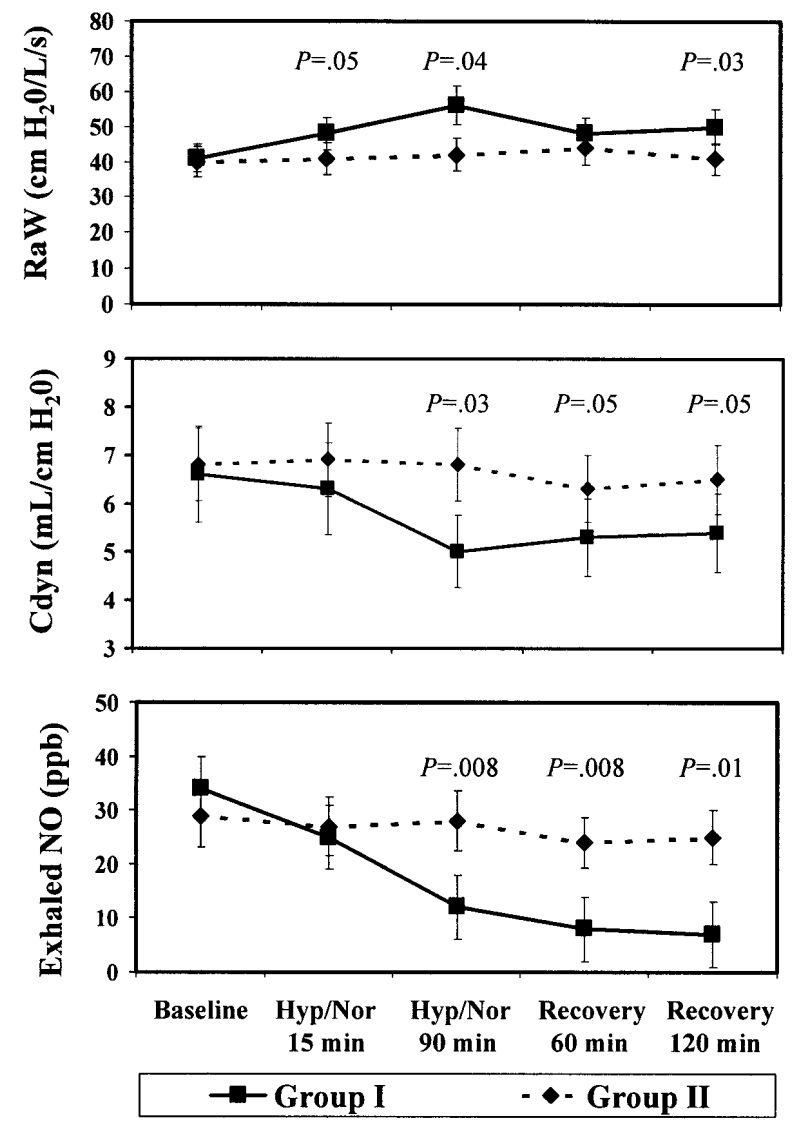

Fig 2. A comparison of changes in inspiratory airway resistance and dynamic airway compliance with exhaled nitric oxide in groups I and II. Top, Inspiratory airway resistance increased during hypoxia in group I and remained elevated after reoxygenation. Center, Dynamic airway compliance in group I decreased during hypoxia and remained depressed after reoxygenation despite a return to normoxia. Bottom, The decrease in airway resistance and dynamic airway compliance in group I was associated with decreased exhaled nitric oxide at end hypoxia and throughout recovery. Airway resistance and dynamic airway compliance did not change in group II throughout hypoxia and recovery. $P$ values are group I versus group II, as determined by using analysis of variance. Hyp/Nor, Hypoxia (group I) or normoxia (group II).

at baseline to $0.24 \pm 0.08 \mathrm{U} / 50 \mathrm{mg}$ of wet tissue at end recovery in group II $(P=.2)$. LPO values were $6.52 \pm 0.79 \mathrm{nmol} / 100 \mathrm{mg}$ of wet tissue at baseline compared with $6.78 \pm 0.86 \mathrm{nmol} / 100 \mathrm{mg}$ of wet tissue at end recovery in group II $(P>.2)$.

\section{Discussion}

Recent evidence indicates that altered exhaled NO levels are associated with various pathologic condi- 

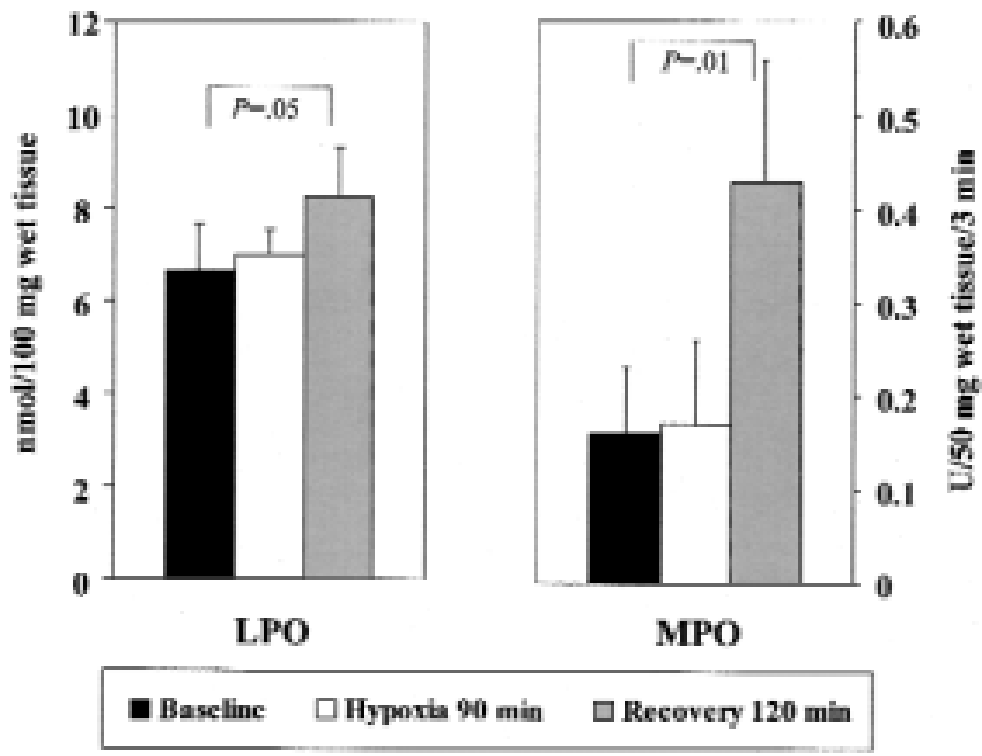

Fig 3. LPO levels and MPO activity in lung tissue from group I animals during hypoxia and recovery. A, Lipid peroxidase levels were increased at end recovery, indicating lipid peroxidation and oxidative stress in lung tissue from group I animals. B, Pulmonary MPO activity, a marker of leukocyte activity, was elevated in the lung tissue collected from group I animals at end recovery, suggesting that reoxygenation resulted in leukocyte-mediated injury.

tions, such as adult respiratory distress syndrome, asthma, congestive heart failure, and endotoxemia. ${ }^{3,12-15}$ Each of these conditions demonstrates changes in PVR and mechanics. Fluctuations in exhaled NO in these various pathologic states might be a useful marker of acute lung injury. ${ }^{16}$

The current study demonstrated that marked decreases in exhaled NO were associated with changes in pulmonary mechanics and increased MPO and LPO in pigs subjected to hypoxia and subsequent reoxygenation on CPB. In addition, to test whether changes in exhaled NO correspond to decreased pulmonary vascular or systemic NO production, both aortic and pulmonary arterial nitrite levels were measured as an estimate of NO production. No association was found between aortic or pulmonary arterial nitrite levels and exhaled NO after reoxygenation.

Our findings supported the proposed concept that exhaled NO correlates poorly with plasma nitrite levels. ${ }^{17,18}$ There was a persistent decline in exhaled NO after reoxygenation, whereas both aortic and pulmonary arterial nitrite measurements returned to baseline levels. The significance of exhaled NO and the relationship to plasma nitrite levels remains controversial. One explanation for the divergence in exhaled NO and plasma nitrite levels is that exhaled NO reflects airway NO production generated by NOS II, which is constitutively expressed in bronchial epithelium, ${ }^{19}$ whereas plasma nitrite presumably reflects NO produced either from the pulmonary endothelium, systemic NO production, or both. In support of this concept is the fact that hemoglobin binds NO with high affinity and reduces it to nitrate and nitrate, thereby curtailing the crossing of pulmonary arterial NO into the bronchial tree. ${ }^{17,18}$

Acute pulmonary injury from hypoxia-reoxygenation might adversely affect bronchial NOS II activity, whereas vascular NOS, which is derived from many sources in the body, might not be affected to the same degree. The decrease in both aortic and pulmonary arterial nitrite during hypoxia was associated with decreases in exhaled NO. This is consistent with what is known regarding the effect of hypoxia on NOS activity. However, once normoxic condition returned, both pulmonary arterial and aortic nitrite levels increased back to baseline values, suggesting recovery of pulmonary endothelial NOS activity and NO production. In contrast, exhaled NO remained depressed, actually decreasing further after reoxygenation. Because NO produced by vascular endothelium is rapidly reduced by hemoglobin rather than readily passing into the alveolus, we believe that the changes occurring in exhaled NO represented a distinct process. ${ }^{17,18}$ Studies are currently underway to look specifically at bronchial NOS II activity compared with pulmonary NOS activity in this model. 
Although measurement of plasma nitrite and nitrate is an accepted method of estimating blood levels of NO, this method somewhat limits the attempts to compare changes in exhaled NO with blood NO levels. Inferences from nitrite measurements must be viewed cautiously because nitrite measurements are only a marker of NO levels. The lack of an easily applied in vivo method to directly measure NO levels in the blood is a limiting factor in studies looking at in vivo NO changes. Furthermore, because of the longer half-life of nitrite compared with NO itself and because of the difference in sample number for the pulmonary arterial and aortic nitrite values, no conclusions can be inferred from attempts to determine a transpulmonary gradient of nitrite. However, the postreoxygenation increase in both pulmonary arterial and aortic nitrite compared with the continued decline of exhaled NO does appear significant.

In our model the dual insults of hypoxia and subsequent reoxygenation on $\mathrm{CPB}$ resulted in more pronounced acute lung injury than $\mathrm{CPB}$ alone, which resulted in trivial alterations in pulmonary mechanics and PVR and no change in exhaled NO. There is significant variation, especially in animal studies, regarding the effect of CPB on pulmonary function. However, the absence of significant injury after CPB alone in our model is supported both by other animal studies ${ }^{20,21}$ and clinical experience in which patients are commonly extubated within 12 hours of surgery with minimal pulmonary changes. The use of an identical bypass circuit and oxygenator to those used clinically in our institution, the lack of significant cooling, the use of proper donor blood handling and storage, and the participation of a clinical perfusionist minimized the effect of CPB in our model and provided a clinically relevant and consistent method of reoxygenation. It has been suggested that CPB alone might decrease exhaled NO levels. Beghetti and colleagues ${ }^{22}$ demonstrated a modest decrease in exhaled NO from children undergoing CPB. However, inhalational anesthetics that are known to decrease exhaled NO are often used in clinical settings and might contribute to a decrease in exhaled NO production. In the current study exhaled NO levels did not change during or after CPB in the control animals.

Baseline exhaled NO levels in the current study were within the range of 20 to $35 \mathrm{ppb}$, which was previously measured in human beings and animals. ${ }^{12,23}$ With the onset of hypoxia, exhaled NO progressively decreased with reduced inspired oxygen. This was consistent with the findings of Nelin and associates, ${ }^{12}$ who demonstrated decreased exhaled NO during hypoxia in an isolated piglet lung model. A similar decrease in exhaled NO was also seen when the NOS inhibitor $N$-nitro-L- arginine methyl ester (L-NAME) was administered to normoxic control lungs. Other researchers have shown a similar, although more modest, decrease in exhaled NO with moderate hypoxia and a more marked decrease when $\mathrm{FIO}_{2}$ was below 5\%. The rapid decrease in exhaled NO associated with hypoxia might be a direct inhibitory effect of inspired $\mathrm{FIO}_{2}\left(\right.$ alveolar $\left.\mathrm{PO}_{2}\right)$ or pulmonary arterial $\mathrm{PO}_{2}$ on NOS II activity. ${ }^{24}$ In contrast, the continued decrease in exhaled NO detected during reoxygenation and recovery might be due to bronchial epithelial injury.

Decreased exhaled NO levels have been associated with altered pulmonary mechanics in numerous pathologic conditions. ${ }^{4,12-14}$ Changes in exhaled NO might be a marker of airway disease and injury, as well as an indicator of the effectiveness of therapy. In this study decreased exhaled NO was associated with decreased pulmonary compliance and increased airway resistance despite a fixed tidal volume.

A unifying explanation of the data is that hypoxiareoxygenation injury resulted in bronchial epithelial injury and dysfunction, led to decreased exhaled NO production, and contributed to altered airway resistance and pulmonary compliance. Increased MPO activity and LPO levels after reoxygenation implied that leukocyte-mediated reoxygenation injury occurred. It was notable that animals subjected to CPB without preceding hypoxia did not have increased MPO activity or LPO levels. It is likely that reoxygenation injury was not limited to the bronchial epithelium and that other areas of the lung, such as the pulmonary vascular endothelium, might also have been affected.

This study demonstrated that decreased exhaled NO was associated with altered pulmonary mechanics during hypoxia. Furthermore, there was a poor association between plasma nitrite levels and exhaled NO, suggesting two distinct entities. After reoxygenation, exhaled NO levels remained depressed, possibly indicating bronchial epithelial injury. Bronchial epithelial dysfunction and decreased bronchial NO production might contribute to the persistent changes in pulmonary mechanics detected after hypoxia and reoxygenation.

\section{REFERENCES}

1. Alving K, Weitsburg E, Lundberg JM. Increased amounts of nitric oxide in exhaled air of asthmatics. Eur Respir J 1993;6: 1368-70.

2. Kharitonow SA, Yates AD, Robbins RA, Logan-Sinclair R, Shinebourne EA, Barnes PJ. Increased nitric oxide in exhaled air of asthmatics. Lancet 1994;343:133-5.

3. Hugman M, Frostell H, Hedenstrum H, Hedenstierna G. Inhalation of nitric oxide modulates adult human bronchial tone. Am Rev Respir Dis 1993;148:1474-8. 
4. Brett SJ, Evans TW. Measurement of endogenous nitric oxide in the lungs of patients with acute respiratory distress syndrome. Am J Respir Crit Care Med 1998;157:993-7.

5. Kharitonow SA, Cailes JB, Black CM. Decreased nitric oxide in the exhaled air of patient with systemic sclerosis with pulmonary hypertension. Thorax 1998;52:1051-5.

6. Kobzik L, Bredt DS, Lowenstein CJ, Drazen J, Gaston B, Sugarbaler D, et al. Nitric oxide synthase in human and rat lung: immunocytochemical and histochemical localization. Am J Respir Cell Mol Biol 1993;9:371-7.

7. Pearl JM, Wellman SA, McNamara JL, Lombardi JP, Wagner CJ, Raake JL, et al. Bosentan prevents hypoxia-reoxygenationinduced pulmonary hypertension and improves pulmonary function. Ann Thorac Surg 1999;68:1714-22.

8. Robbins RA, Floreani AA, Von Essen SG. Measurement of exhaled nitric oxide by three different techniques. Am J Respir Crit Care Med 1996;153:1631-5.

9. Ihnken K, Morita K, Buckberg GD, Sherman MP, Young HH. Studies of hypoxemic/reoxygenation injury: without aortic clamping. VI. Counteraction of oxidant damage exogenous antioxidants: $N$-(2-mercaptopropionyl)-glycine and catalase. J Thorac Cardiovasc Surg 1995;110:1212-20.

10. Langregr JM, Murase N, Markus PM. Nitric oxide production in host-versus-graft and graft-versus-host reactions in the rat. J Clin Invest 1992;90:679-83.

11. Guarner C, Soriano G, Tomas A. Increased serum nitrite and nitrate levels in patients with cirrhosis: relationship to endotoxemia. Hepatology 1993;18:1139-43.

12. Nelin LD, Thomas CJ, Dawson CA. Effect of hypoxia on nitric oxide production in neonatal pig lung. Am J Physiol 1996;271: H8-14.

13. Gustafsson LE, Leone AM, Persson MG, Wiklund NP, Moncada S. Endogenous nitric oxide is present in the exhaled air of rabbits, guinea pigs, and humans. Biochem Biophys Res Commun 1991; 181:852-7.
14. Borland C, Cox Y, Higenbottam T. Measurement of exhaled nitric oxide in man. Thorax 1993;48:1160-2.

15. Dahm PL, Jonson B, De Robertis W, Myhre E, Svantesson C, Thorne J, et al. The effects of nitric oxide inhalation on respiratory mechanics and gas exchange during endotoxaemia in the pig. Acta Anaesthesiol Scand 1998;42:536-44.

16. Barnes PJ, Kharitonow SA. Exhaled nitric oxide: a new lung function test. Thorax 1996;51:233-7.

17. Persson MG, Gustafsson LE, Wiklund NP, Moncada S, Hedqvist P. Endogenous nitric oxide as a probable modulator of pulmonary circulation and hypoxic pressor response in vivo. Acta Physiol Scand 1990;140:449-57.

18. Hyde RW, Geigel EJ, Olszowka JA. Determination of production of nitric oxide by lower airways of humans-theory. J Appl Physiol 1997;82:1290-6

19. Ali S, Metzger WJ, Olanrewaju HA, Mustafa SJ. Adensoine receptor-mediated relaxation of rabbit airway smooth muscle: a role for nitric oxide. Am J Physiol 1998;273:581-7.

20. Ihnken K, Morita K, Buckberg GD. Delayed cardioplegic reoxygenation reduces reoxygenation injury in cyanotic immature hearts. Ann Thorac Surg 1998;66:177-82.

21. Ihnken K, Morita K, Buckberg GD, Winkelmann B, Schmitt M, Ignarro $\mathrm{LJ}$, et al. Nitric-oxide-induced reoxygenation injury in the cyanotic immature heart is prevented by controlling oxygen content during initial reoxygenation. Angiology 1997;48:189-202.

22. Beghetti M, Silkoff PE, Caramori M, Holtby HM, Slutsky AS, Adatia I. Decreased exhaled nitric oxide may be a marker of cardiopulmonary bypass-induced injury. Ann Thorac Surg 1998;66: 532-4.

23. Carlin RE, McGraw DJ, Camporesi EM. Increased nitric oxide in exhaled gas is an early marker of hypovolemic states. J Surg Res 1997;69:362-6.

24. Guo FH, Erzurum SC. Characterization of inducible nitric oxide synthase expression in human airway epithelium. Environ Health Perspect 1998;106:1119-24.

\section{Timely}

The Journal of Thoracic and Cardiovascular Surgery delivers the information you need now. Articles usually appear within four months of acceptance. 